\title{
Location characteristics and differentiation
} mechanism of logistics nodes and logistics enterprises based on points of interest (POI): A case study of Beijing

\author{
LI Guoqi ${ }^{1}$, "JIN Fengjun², CHEN Yu ${ }^{3}$, JIAO Jinjuan ${ }^{4}$, LIU Sijing ${ }^{1}$ \\ 1. School of Transportation \& Logistics, Southwest Jiaotong University, National United Engineering Laboratory \\ of Integrated and Intelligent Transportation, Chengdu 610031, China; \\ 2. Institute of Geographic Sciences and Natural Resources Research, CAS, Beijing 100101, China; \\ 3. School of Geographic Science, Nanjing Normal University, Nanjing 210031, China; \\ 4. School of Economics and Management, Beijing Jiaotong University, Beijing 100044, China
}

\begin{abstract}
The logistics nodes and logistics enterprises are the core carriers and organizational subjects of the logistics space, and their location characteristics and differentiation strategies are of key importance to optimizing urban logistics spatial patterns and ensuring reasonable resource allocation. Based on Tencent Online Maps Platform from December 2014, 4396 logistics points of interest (POI) were collected in Beijing, China. By the methods of industrial concentration evaluation and kernel density analysis, the spatial distribution pattern of logistics in Beijing are explored, the interaction mechanism among the type difference, supply-demand side factors and location choice behavior are clarified, and the internal mechanism of spatial differentiation under the combined influence of transportation, land rent and assets are revealed. The following conclusions are drawn in the paper. (1) Logistics enterprises and logistics nodes exhibit the characteristic of both co-agglomeration and spatial separation in location, and logistics activities display the spatial pattern of "marginal area of downtown area, suburbs and exurban area", which have a weak coupling degree with logistics employment space. (2) The public logistics space, namely, logistics parks and logistics centers, is produced under the guidance of the government, and the terminal logistics space consisting of logistics distribution centers serving for the specific industries and terminal users is dominated by enterprises. The locational differentiation between the two modes of logistics space is significant. (3) In the formation of the logistics spatial location, the government can change the traffic condition by re-planning the transport routes and freight station locations, and control the land rent and availability of different areas by increasing or decreasing the land use of logistics, to impact the enterprise behavior and form different types of logistics space and function differentiation. In comparison, logistics enterprises meet the diverse demands of service objects through differentiation of asset allocation to promote the specialization of division and form the object differentiation of logistics space.
\end{abstract}

Keywords: spatial differentiation; logistics node; logistics enterprise; asset specificity

Received: 2016-12-21 Accepted: 2017-02-10

Foundation: National Natural Science Foundation of China, No.41501123, No.71703219

Author: Li Guoqi (1984-), PhD, specialized in geography of logistics and spatial analysis. E-mail: guoqi@swjtu.edu.cn

"Corresponding author: Jin Fengjun (1961-), PhD and Professor, E-mail: jinfj@igsnrr.ac.cn 


\section{Introduction}

The logistics industry is a fundamental, strategic and leading service industry with spatial distribution across Earth's surface. Logistics activities are involved in diverse sectors including agriculture, industry, business services and transportation. Logistics nodes that serve as the core carriers of logistics space, and logistics enterprise as the organizational subjects of logistics space, exhibit pronounced spatial selection behavior (Wang, 2014). Influenced by new location factors and organization modes, existing transport geography and commercial geographic theories have encountered difficulties in systematically interpreting logistics space problems (Allena et al., 2012).

At different stages during the evolution of logistics, the focus of the logistics of geographic research changed significantly at home and abroad. At the stage of physical distribution, the research focused on the location choice of distribution warehouses for manufacturing enterprises and distribution centers for commercial and trade enterprises (Sule, 2001; Liu et al., 2000). At the stage of integrated logistics management, the layout of logistics parks and centers with public service functions became the focal point of research (Taniguchi et al., 1999; Yuan et al., 2001). At both stages described above, the emphasis was on optimization problems of the location and layout of the logistics nodes, and the fields of the research were mostly focused on urban areas and specific enterprises. Logistics has entered the era of supply chain in the 21 st century. Geographers are increasingly becoming an important force in the research of logistics locations. Current research focuses on multi-scale locational restructuring in logistics enterprises and logistics nodes (Wang, 2014; Hesse et al., 2004). Metropolitan areas attracted multifaceted research by various scholars, because these areas are the main source of logistics demands and the major layout area of logistics enterprises and nodes (O'Connor, 2010; Van den Heuvel et al., 2013). The representative viewpoints include: logistics nodes are agglomerating towards the vicinity of transportation infrastructures such as harbor, airport, and highway, as well as inner suburbs, transportation corridor and outer suburban regions surrounding continental metropolitan areas. These arrangements are structured to facilitate connection with regional and national freight flow (Rivera et al., 2014; Rivera et al., 2016; Verhetsel et al., 2015; Pan et al., 2012). The agglomeration of logistics nodes towards metropolitan areas expedites the spatial restructuring of logistics activities, the increase in logistics land use, and the reorganization of freight flow (Cao, 2011; Dablanc et al., 2014). In general, locations of logistics nodes and logistics enterprises show both "sprawl" and "polarization" behaviors (Takanori et al., 2015; Dablanc et al., 2012).

Distinct differences exist between domestic and international logistics research concerning the areas of emphasis and data source. In developed countries such as Japan, America, and those in Europe, logistics are highly market-oriented and centralized industries. Logistics enterprises are in general agglomerated inside logistics nodes. Under such conditions, research focuses on the problems in logistics agglomeration and locations of logistics nodes. The data used in such studies are mainly logistics statistics data by zip code and enterprise survey data. The concept of modern logistics was introduced in China during the 1980s, and centralized operation of public logistics nodes represented by logistics parks and logistics centers were mainly established in the "12th Five-Year Plan" period (2011-2015). The existing research focused on the location characteristics, influencing factors, as well as the formation mechanisms of logistics enterprises. The logistics nodes were treated as specific 
functional types of logistics enterprises. The importance of governmental behavior on the formation of logistics nodes and distributions of logistics enterprises was not systematically revealed (Pan et al., 2012; Cao, 2011; Wang, 2008; Cao, 2012; Zhao et al., 2009).

Research data were obtained domestically from small sample-sized questionnaires, yellow pages and business registration information etc. These data are insufficient in sample size and difficult to use in the empirical analysis. Currently, logistics activities are changing rapidly in the global multi-scale space. The logistics development focus is shifting towards the Asia-Pacific region. Logistics activities in China are especially experiencing significant changes impacted by the new economy. Thus, there is an urgent need to improve location theory and empirical analysis of logistics activities (Wang, 2014; Verhetsel et al., 2015) in order to explain a series of new issues. These include the spatial mechanisms of action and evolution of logistics enterprises and nodes under the influence of different behavior subjects.

Spatial information science is based on $3 \mathrm{~S}$ and other information technologies, and performs acquisition, storage and management of spatial data. Its theory and method gives new vitality to location analysis (Virginia, 2014). In China, due to the accelerated growth of both E-commerce enterprises such as Alibaba, Jingdong etc., and location-based service providers such as Tencent, AutoNavi, Baidu etc., there have been revolutionary reforms to the organization models of logistics enterprises. At the same time, it also gave rise to problems such as elevated conflicts in logistics land use, and "last mile" distribution challenges (Zhao et al., 2009). All of these trends highlight the impact of new factors on logistics locations, provide a new route for the acquisition and processing of logistics geographic information, and bring novel opportunities to logistics location research in China. After the logistics planning and implementation during the "10th, 11th and 12th Five-Year Plan" periods (2001-2015), Beijing has preliminarily built several logistics parks including Shunyi Airport, Tongzhou Majuqiao, Pinggu Mafang and Daxing Beijing South, as well as a number of distribution centers such as Shibalidian, etc. Through efforts such as these, a basic urban logistics space has been formed. In the context of Beijing-Tianjin-Hebei coordinated development, adjustment of the capital logistics functions is imperative. Taking Beijing as a case study, its logistics points of interest (POI) were collected. The location characteristics and differentiation mechanism of logistics nodes and enterprises were then identified, which could provide references for the adjustment of logistics functions and layout optimization, and help further studies to perfect logistics location theory.

\section{Data source and research methods}

\subsection{Data source and processing}

Based on the cognition of the theory of logistics elements in the Material Flow by Professor and Academician Xu Shoubo, logistics nodes act as the basic elements of logistics system, and provide the operation space for logistics activities. Logistics enterprises act as organizational elements in logistics system, and are the main operators of logistics activities. The logistics spatial location formed by logistics nodes and logistics enterprises constitutes the core of logistics location theory (Xu, 2007). Currently, a broad consensus has not yet been reached regarding the connotation and classification of logistics nodes and logistics enterprises, and this has restricted empirical studies on the microscopic scale. Therefore, the re- 
search samples are first classified and encoded based on different criteria as detailed below. First, according to the national standard GB/T 18354-2006 for logistics terms, the logistics nodes are divided into three categories, including logistics parks, logistics centers and distribution centers. These nodes are then further assorted into "government-planned" or "enterprise self-built", according to difference in main bodies. In addition, freight stations have long been in existence as traditional logistics nodes before the concept of modern logistics was introduced and specialized logistics nodes were built. Therefore, freight stations are included as a new sub-category of logistics nodes in consideration of their existing role as important carriers of logistics activities. Freight stations are then classified into four groups on the basis of modes of transportation, and are considered as the main supply-side factor for the location choice of the previous three subcategories of logistics nodes. Second, in reference to National Standard GB/T 19680-2005 for the classification and evaluation indicators for logistics enterprises, and combining domestic and international classification criteria for logistics enterprises from academia and industries (Mao et al., 2005; Ru et al., 2014), logistics enterprises were categorized into five groups. These groups include express and postal, storage and transportation, freight forwarders, comprehensive logistics and others. Express and postal companies, and storage and transportation companies are each further sub-divided into two subgroups based on their main businesses. Third, many traditional logistics nodes have already been in the transportation system before the formation of the modern logistics nodes, and the concept of logistics was introduced into China not long ago. Moreover, the locations of logistics enterprises and nodes are highly dependent on transportation facilities and customers' demands. Further, the close association between logistics activities and international trade has gradually increased. Considering all the aforementioned factors, transportation, customs-bonded facilities, industrial parks and professional markets are included as four classes of facilities relevant to logistics activities. Industrial parks and professional markets were considered as the main demand-side factor for the location choice by logistics enterprises and nodes. There was no overlapping among enterprises and facilities in their classification and coding. The results are shown in Table 1.

Table 1 Classification and coding of research samples

\begin{tabular}{lll}
\hline \multicolumn{1}{c}{ Class } & \multicolumn{1}{c}{ Category } & \multicolumn{1}{c}{ Subcategory (Coding) } \\
\hline $\begin{array}{l}\text { Logistics } \\
\text { nodes }\end{array}$ & Logistics parks/bases & Government-planned (010), Enterprise self-built (011) \\
$(\mathrm{LN})$ & Logistics centers & Government-planned (020), Enterprise self-built (021) \\
& Distribution centers & Unclassified (040) \\
& Freight stations & Railway freight station (031), Highway freight station (032), \\
& & Water transport depot (033), Air cargo terminal (034) \\
Logistics & Express and postal services & Express enterprises and service points (110), Postal enterprises \\
enterprises & & and service points (111) \\
$($ LE) & Storage and transportation & Transportation and distribution (120), Storage (130) \\
& Freight forwarders & Unclassified (140) \\
& Comprehensive logistics & Unclassified (150) \\
& Others & Unclassified (160) \\
Logistics & Customs-bonded facilities & Special area or warehouse for intendance by customhouse (050) \\
related & Transportation terminals & Airport (060), Port (070) \\
facilities & Industrial parks & Unclassified (080) \\
(LF) & Professional markets & Unclassified (090) \\
\hline
\end{tabular}


We collected basic logistics data in December 2014 on traffic network and road stations by employing the Tencent Maps open API platform. "Logistics", "transport", and "postal express" are used as key words. 4396 logistics POIs were collected within 16 urban, suburban, and rural districts of Beijing (Figure 1). This data includes 405 logistics nodes, 3953 logistics enterprises and 38 logistics-related facilities.

\subsection{Methods}

We took "regional spatial pattern identification-influence factor recognition-key factor extraction" as the

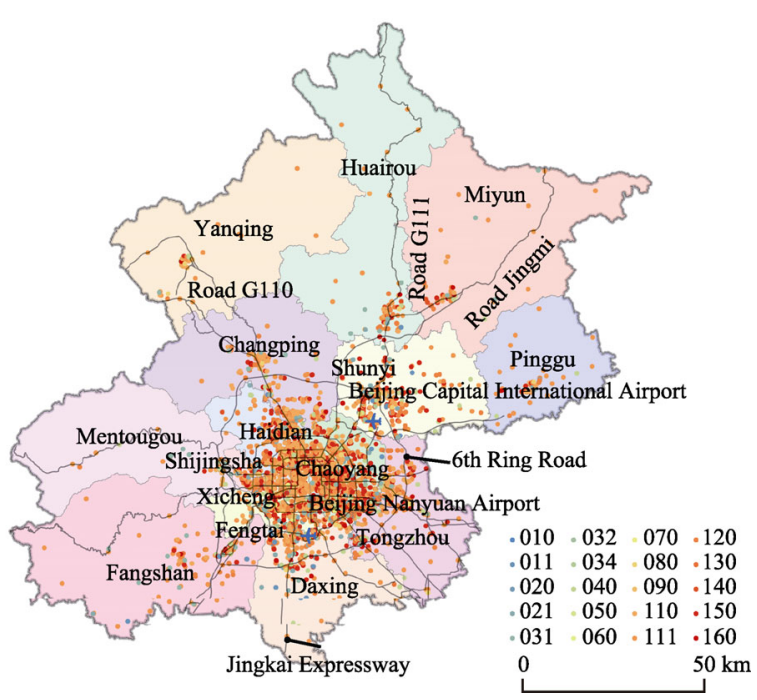

Figure 1 Spatial distribution of the POIs by type core of this research contents. First, we revealed the logistics spatial patterns of Beijing by using improved logistics cluster identification by Professor Yossi Sheffi at MIT that combines industry concentration evaluation methods including Location Quotient (LQ), Horizontal Cluster Location Quotient (HCLQ), Locational Gini Coefficient (LGC) and Herfindahl-Hirschman Index (HHI) (Van den Heuvel et al., 2013; Rivera et al., 2014), as well as kernel density analysis method. Second, descriptive statistical methods such as average distance and distance/frequency distribution were used to reveal the relationship between type difference and location choice. Cumulative analysis, density distribution and buffer analysis were used to reveal the interaction between supply-demand side factors and location choice behaviors. Finally, traffic location theory, land rent theory and asset specificity theory were used to systematically understand the spatial differentiation mechanism of logistics nodes and logistics enterprises. Figure 2 shows the research framework.

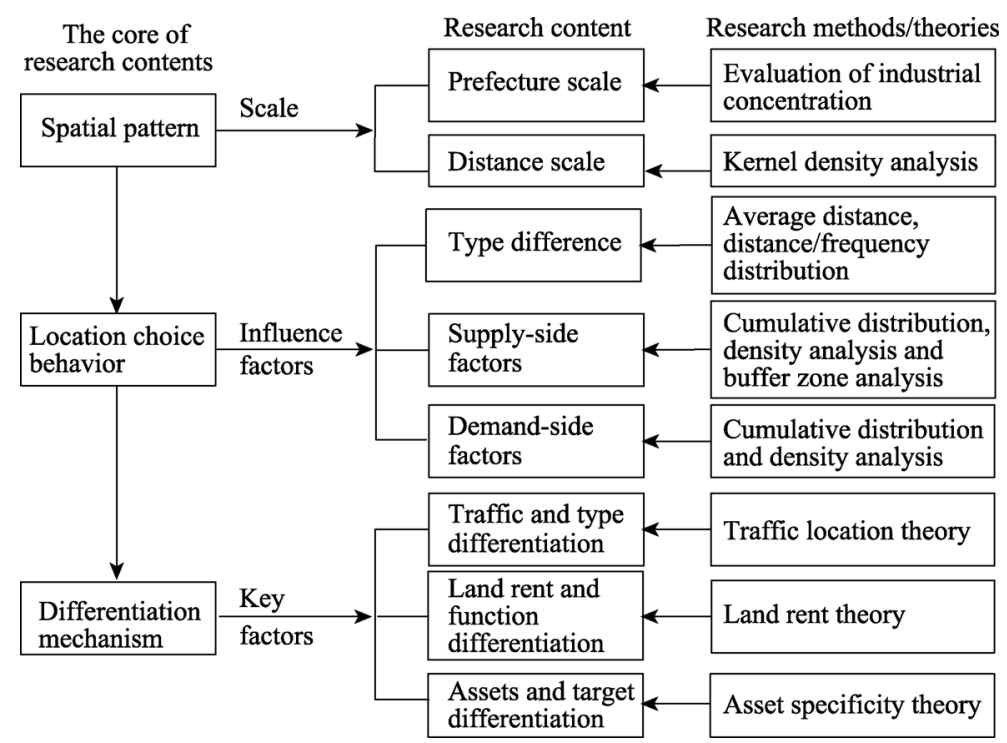

Figure 2 Research framework 


\section{Logistics spatial distribution patterns based on multi-scales}

\subsection{Logistics space in Beijing shows location characteristics of both co-agglomeration and spatial separation, and a weak coupling degree with logistics employment space}

Based on the logistics POI data in Beijing and the data of employment in transportation, storage and postal industries from National Census data in 2010, we can draw the following conclusions from the descriptive statistics and the evaluation of industrial concentration (Table 2):

Table 2 Evaluation of the degrees of concentration of the logistics industry in Beijing

\begin{tabular}{|c|c|c|c|c|c|}
\hline & $\mathrm{LN}+\mathrm{LE}$ & LN & LE & LQ & HCLQ \\
\hline Dongcheng District & 0.0478 & 0.0090 & 0.0524 & 1.6977 & 160.0302 \\
\hline Xicheng District & 0.0469 & 0.0119 & 0.0476 & 1.7485 & -216.4864 \\
\hline Chaoyang District & 0.2262 & 0.1791 & 0.2464 & 1.4559 & 8728.7908 \\
\hline Fengtai District & 0.1203 & 0.1701 & 0.1161 & 1.3685 & 14994.0000 \\
\hline Shijingshan District & 0.0166 & 0.0090 & 0.0172 & 1.5007 & 1507.4304 \\
\hline Haidian District & 0.1292 & 0.0687 & 0.1353 & 1.7661 & 12279.4097 \\
\hline Mentougou District & 0.0063 & 0.0179 & 0.0056 & 1.4671 & 564.8173 \\
\hline Fangshan District & 0.0229 & 0.0239 & 0.0228 & 1.2129 & 929.0580 \\
\hline Tongzhou District & 0.0616 & 0.0806 & 0.0615 & 1.0628 & 425.0280 \\
\hline Shunyi District & 0.0849 & 0.1552 & 0.0787 & 1.2615 & 1329.5240 \\
\hline Changping District & 0.0506 & 0.0269 & 0.0519 & 1.8259 & 7097.4581 \\
\hline Daxing District & 0.1294 & 0.2000 & 0.1065 & 0.8515 & -1139.0069 \\
\hline Huairou District & 0.0198 & 0.0119 & 0.0205 & 0.8920 & -218.2477 \\
\hline Pinggu District & 0.0142 & 0.0179 & 0.0139 & 1.0426 & 101.6286 \\
\hline Miyun County & 0.0145 & 0.0090 & 0.0149 & 0.9069 & -241.8358 \\
\hline Yanqing County & 0.0089 & 0.0090 & 0.0089 & 0.9981 & -3.2521 \\
\hline
\end{tabular}

(1) Some $61.79 \%$ of the logistics nodes and $60.43 \%$ of the logistics enterprises are distributed in Chaoyang District, Fengtai District, Haidian District and Daxing District, showing a significant co-agglomeration. These POIs are manifested as highway, railway, airport and freight station locations, and are located in Chaoyang District, Fengtai District and Shunyi District, with their functions as logistics nodes with proportions of $17.91 \%, 17.01 \%$ and $15.52 \%$ of the POIs, respectively. This demonstrates the important impact of traditional logistics nodes on new consolidation centers. Because of the outward relocation of urban freight transport and land space constraints, the attractiveness of Fengtai District to logistics enterprises decreased, with a proportion of 5.4\% less when compared to logistics nodes. Haidian District, as the high-tech industrial development zone, and Daxing District, as the national economic and technological development zone, comprise $6.87 \%$ and $20 \%$ of the logistics nodes, respectively. This finding is consistent with the fact that the logistics demand is much higher in economic development zones than high-tech zones. Haidian District, a science and education center on the fringe of the central urban area, and Daxing District, a 
satellite city in the urban outer suburb, show opposite trends in terms of logistics enterprise consolidation. $13.53 \%$ and $10.65 \%$ of the logistics enterprises are located at these two locations, respectively, which reflected the location orientation towards office space for logistics enterprises.

(2) There is a weak coupling degree between the low aggregation of the Beijing logistics employment space and the logistics nodes and logistics enterprises space, which is consistent with the status quo of serious separation between home and workplace and the long average commuting time in the Beijing municipal area (Meng, 2009). Dongcheng District and Xicheng District, located in the downtown area, and Changping District, with large and dense residential areas, show high LQ and are subject to urban land use allocation and function orientation. Therefore, these districts are not the main consolidation points for logistics nodes and enterprises. Haidian District, Chaoyang District and Fengtai District, located in the fringe of the central urban area, have relatively higher LQ and HCLQ, and correspond with logistics nodes and logistics enterprises' space. At the same time, the LCG value (0.1536) and the HHI value (0.0980) further show the dispersion in Beijing's logistics employment population, which contradicts the spatial distribution, the logistics nodes and logistics enterprises' spatial agglomeration and distribution characteristics, reflecting the high mobility of Beijing's logistics employment population.

\subsection{Logistics activities in Beijing show a spatial pattern of "marginal area of down- town area, suburbs and exurban area"}

Based on the classification results in Table 1, spatial pattern of different types of logistics based on kernel density analysis are revealed (Figure 3), and compared with the planning of
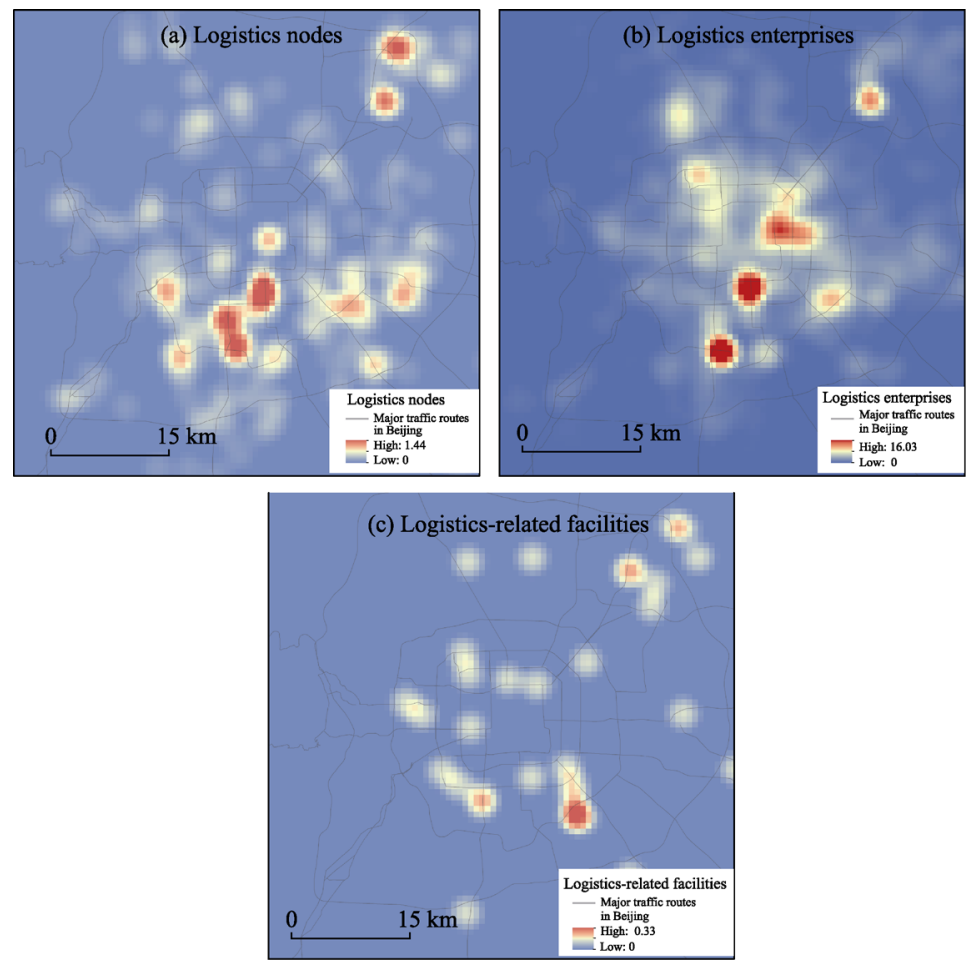

Figure 3 Spatial distribution of different types of logistics based on kernel density analysis 
the logistics node layout in Beijing (Zhang et al., 2010). The results indicate that Beijing logistics activities show a spatial pattern of "marginal area of downtown area, suburbs and exurban area". The locations of logistics nodes showed good adaptability to the planned Beijing public logistics node layout, which are mainly located in two areas. These two areas are within the northeastern 6th Ring Road surrounding the Capital Airport, the economic development area in Fengtai District and Dahongmen area in Daxing District, which are located between the southern 4th Ring Road and southern 6th Ring Road. On the other hand, logistics enterprises are more concentrated than logistics nodes. Logistics enterprises are mainly located in the following areas: commercial office areas in Chaoyang and Haidian Districts between the northern 3rd and 5th ring roads, the economic development areas in Fengtai District, Dahongmen in Daxing District surrounding the southern 4th Ring Road, and the Pinggu Mafang area outside of the southwestern 6th Ring Road. Locations of logistics-related facilities are affected by the layout of railway stations and highway freight stations, showing a low degree of concentration without any obvious trends. However, large-scale logistics facilities that are part of the Beijing's logistics planning, such as highways, railways and airports, exhibit a stronger coupling to logistics nodes and enterprises. These results reflect the influence of the scale of logistics nodes on spatial agglomeration.

\section{Type difference, supply-demand side factors and location choice behaviors}

\subsection{Type difference and hierarchy, imbalance of logistics location space}

For different types of logistics nodes and logistics enterprises, their service targets, asset allocation and service functions are different, and exhibit differentiated location choice behaviors. Studies have shown that the evolution process of logistics nodes and logistics enterprises surrounds the central urban area and the radial road network (Takanori et al., 2015; Dablanc et al., 2012). Beijing has typical road network characteristics with central rings and radial networks sprawling from the center. Tiananmen Square was chosen as the center point to obtain the Euclidean distance of different types of logistics nodes and logistics enterprises

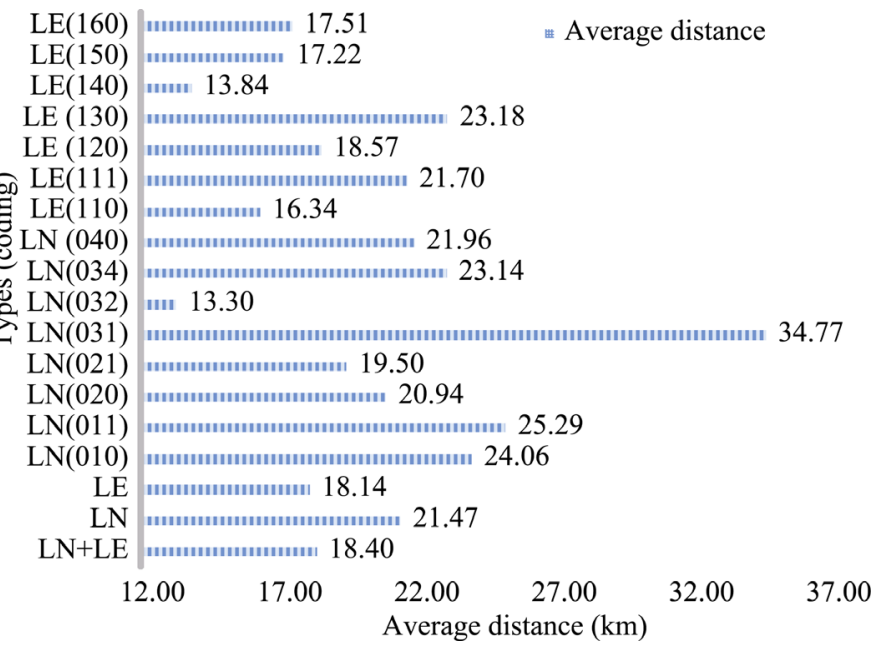

Figure 4 Average distance from different types of logistics nodes and enterprises to the center
POI to this center, then the average distances from the center point (Figure 4) and distance/ frequency distributions of logistics nodes and logistics enterprises were calculated (Figure 5). The average distance of all logistics nodes and logistics enterprises from the center is $18.398 \mathrm{~km}$. The minimum and maximum average distances for different types of logistics nodes and enterprises are $13.297 \mathrm{~km}$ and $34.767 \mathrm{~km}$, respectively (the difference is $21.47 \mathrm{~km}$ ). From the distance/ 
frequency distribution, the highest frequency corresponds to a distance of $15.313 \mathrm{~km}$. The minimum and maximum distances are 1.042 $\mathrm{km}$ and $113.343 \mathrm{~km}$ (the difference is 112.301 $\mathrm{km})$. The logistics space locations exhibit hierarchy and imbalance. Possible reasons are as follows:

(1) The public logistics space, namely, logistics parks and logistics centers, is produced under the guidance of the government, and the terminal logistics space consisting of logistics distribution centers serving for the specific

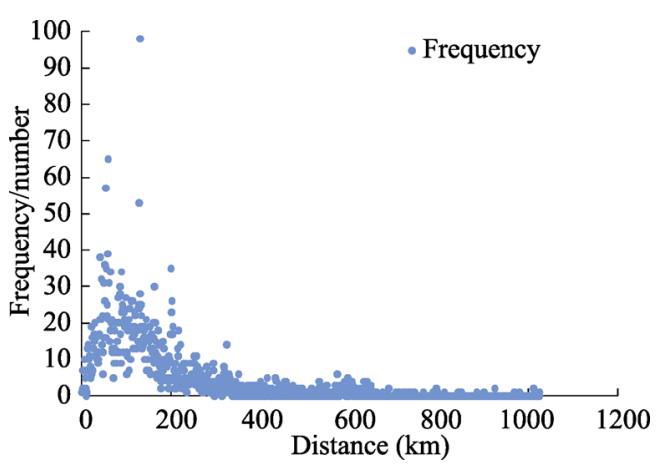

Figure 5 Distance/frequency distribution for all types of nodes and enterprises industries and terminal users is dominated by enterprises. Government-planned logistics parks have the longest distance, which is $2.655 \mathrm{~km}$ further than logistics centers. Such findings are consistent with the hierarchical characteristics of the logistics nodes and the government's guidance on suburbanizing logistics locations (Pan et al., 2012; Zhao et al., 2009). The average distances of enterprise self-built and government-planned logistics parks and logistics centers are similar (differences of 0.5 and $1.4 \mathrm{~km}$, respectively), which reflects the similarity in government and enterprise behaviors. For enterprise self-built distribution centers, the average distance is $21.957 \mathrm{~km}$, which falls between logistics centers and logistics parks. This indicates insufficient government guidance to the terminal distribution nodes, and also reflects the impact of logistics land shortage and high land prices on locating distribution centers near the zones of consumption in central urban areas and inner suburban areas. Such findings are consistent with the current prevailing last mile deliveries difficulties of bigger cities in China (Wang, 2008). Due to the adjustment of city logistics functions and the relocation of freight stations, the railway freight stations are generally located in the exurban area of the city. However, stations as Baiziwan, Shuangqiao and Dahongmen that are responsible for the majority of freight transportation, are still located in the periphery of the central city. Their average distances are close to the highway freight stations set up by Beijing Road Transportation Administration, but are on average further away from the recently built public logistics nodes (the spatial gaps are greater than $5 \mathrm{~km}$ ). This highlights the prevalence of short-distance transport, increased logistics operation links and higher logistics costs in big cities.

(2) Different types of logistics enterprise spaces are influenced by many factors including government planning, service targets, land costs, existing facilities, office environment, etc., resulting in significant differences. Express enterprises mainly serve concentrated residential areas, and the average distance is $16.337 \mathrm{~km}$. Location choice of postal enterprises focuses on a wider scope, and the average distance is greater than the express enterprises (the spatial gaps are greater than $5 \mathrm{~km}$ ). This is consistent with their end-consumer market orientation, and also reflects the universal public service nature of postal services. Transportation and distribution enterprises not only focus on service targets, but also show dependency on logistics nodes, with an average distance of $18.574 \mathrm{~km}$. Storage enterprises are more concerned about the land cost and their connections with government-planned logistics parks, with an average distance of $23.175 \mathrm{~km}$. Most freight forwarders are light asset-based enterprises 
and have the closest distance from the urban areas, with an average distance of only 13.840 $\mathrm{km}$, similar to the average distance of highway freight stations. However, general logistics and other types of enterprises do not show obvious location laws due to the small sample size.

\subsection{Supply side factors and the dynamics, spatial differentiation of logistics location choice}

Eighteen highway freight stations and 16 major railway freight stations were extracted as the key factors of the supply side from Table 1, taking into consideration city scale, radiation of the supply side factor, and stability of the research results. The cumulative distributions of logistics POI within $10 \mathrm{~km}$ were analyzed with $0.5 \mathrm{~km}$ minimum distance interval (Figure 6). The results showed that highway freight stations 7, 8 and 9, and railway freight stations 1, 7, 8, 12 and 13 exhibit a significant agglomeration effect. Among these, the southwest Beijing key highway freight hub, Tongzhou Zhangjiawan hub, and Yizhuang Jingtai logistics center showed the strongest agglomeration ability. Affected by the land use constraints and the increase in rent, the agglomeration degree of traditional railway hubs such as Dahongmen, Fengtai and Baiziwan decreased. Fangshan, Liangxiang, Huairou and other railway stations that are located in the outer suburbs with favorable land use conditions are gradually becoming the new aggregation areas, showing relatively significant dynamics. From the calculation of railway and highway freight station density distribution (Figure 9) in the range of $3 \mathrm{~km}$, highway freight station showed a higher capacity of logistics POI aggregation. In the range of 3-6 km, the change of density tends to stabilize, and the aggregation effect begins to decline. In the range of 6-7 km, the density increases again, which is mostly caused by interference from surrounding stations.

(a) Distribution of highway freight stations

(b) Dstribution of railway freight stations
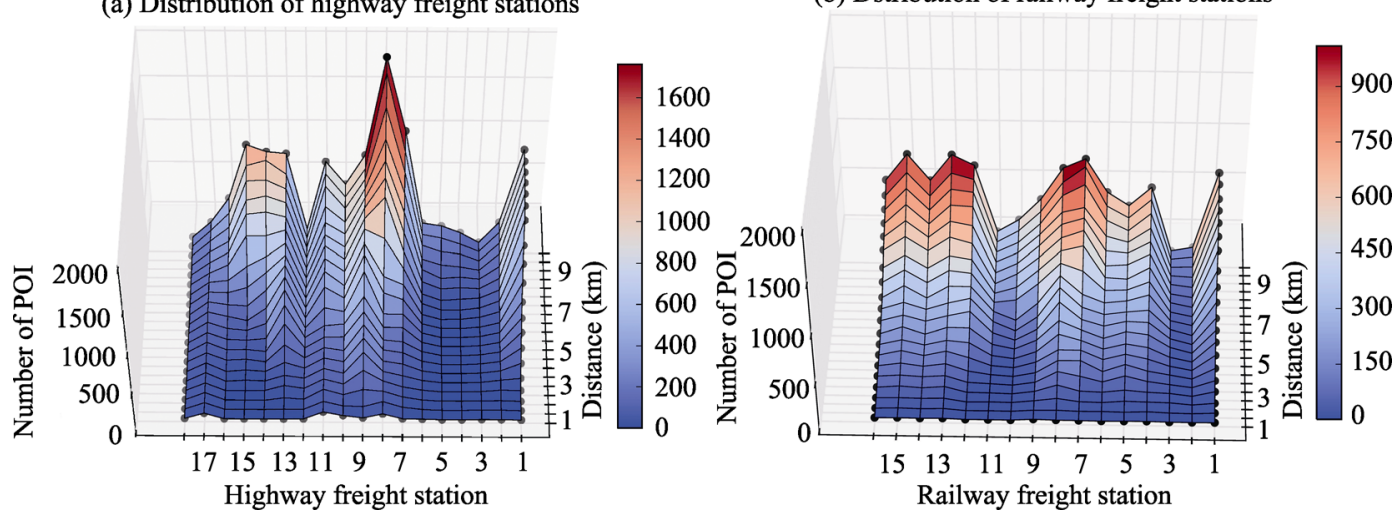

Figure 6 Cumulative distribution of logistics POI at freight stations

While the locations of logistics enterprises and logistics nodes are affected by traditional freight stations, their reliance upon the main traffic network skeleton consisting of main roads and radial roads have caught widespread attention (Verhetsel et al., 2015; Dablanc et al., 2012; Zong et al., 2015a). The six ring roads and skeleton of the radial road network were chosen as the target of analysis with $0.1 \mathrm{~km}$ as the smallest interval unit. Statistical analysis was performed on the agglomeration conditions of logistics nodes and logistics enterprises within the $2 \mathrm{~km}$ buffer zone (Figure 7). 


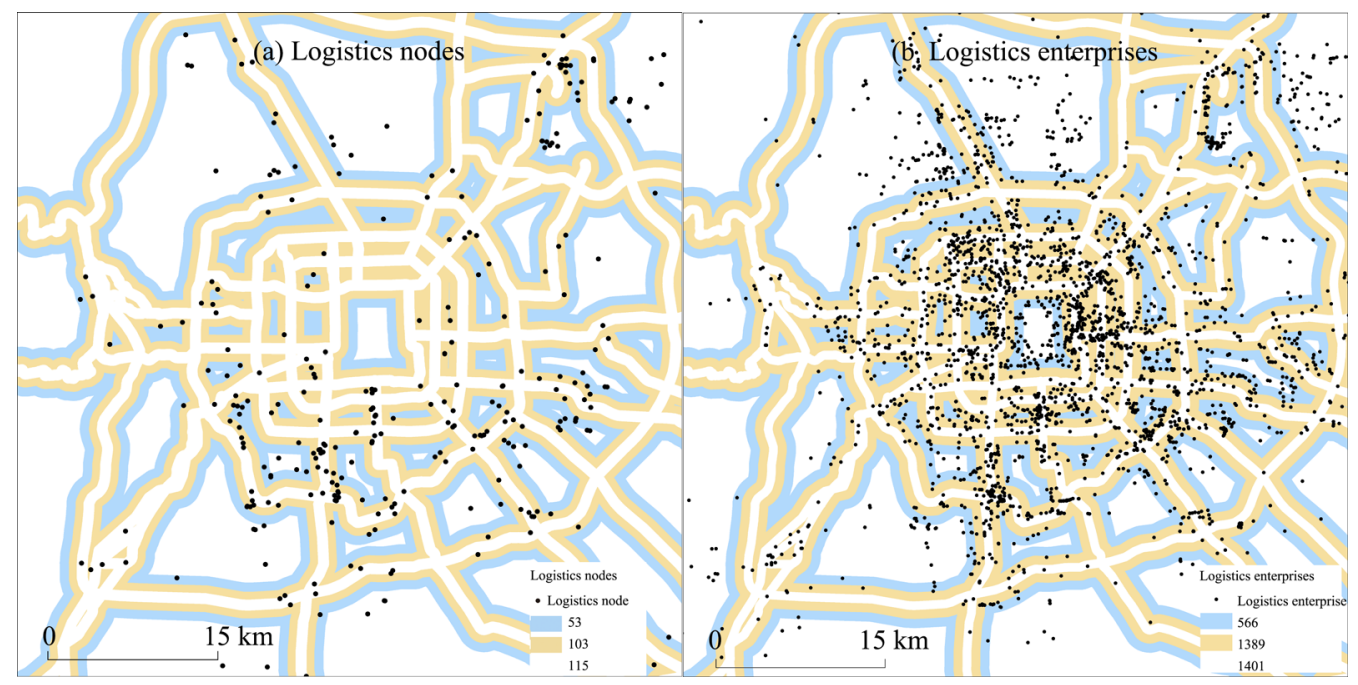

Figure 7 Distribution of logistics node and logistics enterprise locations based on buffer zone analysis

(1) In terms of the relationship between buffer zone and location, logistics nodes and logistics enterprises exhibit similar agglomeration distribution statistics of a "high-mediumlow" pattern. For the former, a high density layer is present from $0-0.5 \mathrm{~km}$; within each unit separated by the minimum interval, the number of agglomerated points ranging between 16-33 accounts for $28.39 \%$ of the total. A medium density layer is observed from $0.5-1.2$ $\mathrm{km}$, with the number of agglomerated points within each unit between 10-19, accounting for $22.96 \%$ of the total. A low density layer is at $1.2-2 \mathrm{~km}$, with the number of agglomerated points for each unit between $4-9$, accounting for $15.55 \%$ of the total. The logistics nodes that aggregate in the buffer zone account for $66.90 \%$ of the total. For logistics enterprises, the high density layer is located at $0-0.4 \mathrm{~km}$, accounting for $35.44 \%$ of the total. The medium density layer is located at $0.4-1.2 \mathrm{~km}$, and the low density layer is located at the same distance as for logistics nodes $(1.2-2.0 \mathrm{~km})$. The logistics enterprises that are located in the buffer zone account for $84.90 \%$ of the total. Logistics enterprises showed slightly stronger dependency on the main traffic network. This is directly caused by the differences in land requirements and asset allocations between the two.

(2) In terms of the relationship between road network and location, the logistics nodes and logistics enterprises are distinctively different, with the trend of suburbanization more significant for logistics nodes. The former mainly agglomerated in ring-shaped roads surrounding the 5th Ring Road, as well as in the vicinity of radial roads such as the Jingkai, Jingshen and Jingcheng highways. The logistics enterprises agglomerated in the ring road around the 3rd and 4th ring roads, as well as the vicinity of the northwest-bound radial roads such as the Beijing-Lhasa (Jingzang) and Beijing-Urumqi (Jingxin) highways. Logistics enterprises show lower sensitivity to the overall rent level than the logistics nodes.

\subsection{Demand side factors and stability, spatial differentiation of logistics location choice}

Eighteen industrial parks and 13 major professional markets in Beijing were extracted as key demand side elements, taking into consideration the size of cities, the size of demand side factors and stability of results. The cumulative distribution of logistics POI within $10 \mathrm{~km}$ was obtained with $0.5 \mathrm{~km}$ minimum interval (Figure 8). 
(a) Distribution of industrial park

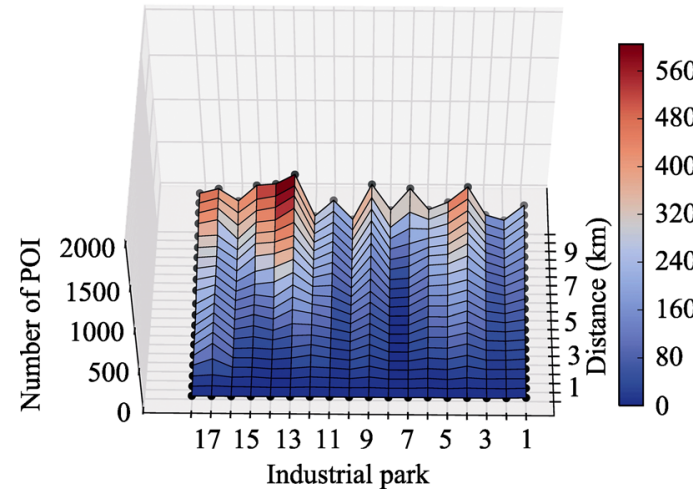

(b) Distribution of professional markets

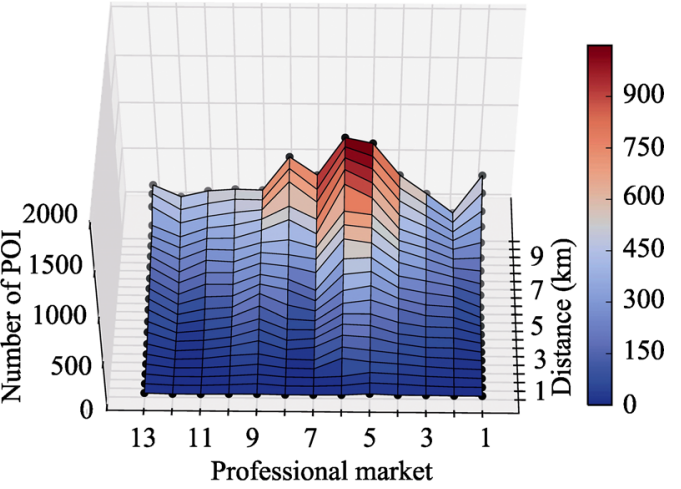

Figure 8 Cumulative distribution of logistics POI for industrial parks and professional markets

The results show that the agglomeration effect was obvious in industrial parks $4,7,9,11$, 13 and 17, and professional markets 1, 5, 6 and 8. Among these data, the agglomeration effect was most significant in the following regions: Daxing Economic Development Zone located at inner suburb of Beijing; Zhongguancun Science Park at Changping District located in an outer suburb of Beijing; Yanqi, Yongle and Badaling Economic Development Zones located in outer suburbs of Beijing. This reflects the suburbanization trend of manufacturing logistics, consistent with the dominance of manufacturing demand. The highest degree of agglomeration was observed at Xinfadi, Baliqiao, Yuquanlu agricultural products wholesale markets and Dinghao Tiandi electronic products wholesale market, all located around the edge of the central urban area. This indicates that the urban commercial logistics are still concentrated around the central urban area, showing a relatively high stability and significant location differentiation compared to the demands for manufacturing logistics. Calculations of the density distribution of different demand types (Figure 10) show that industrial parks have a stronger effect on the logistics POI agglomeration than professional markets within $1 \mathrm{~km}$, indicating that Beijing has a high degree of integration between manufacturing and logistics, and that industrial parks have abundant logistics land with relatively low land prices. On the other hand, the lack of supporting capacity for commercial

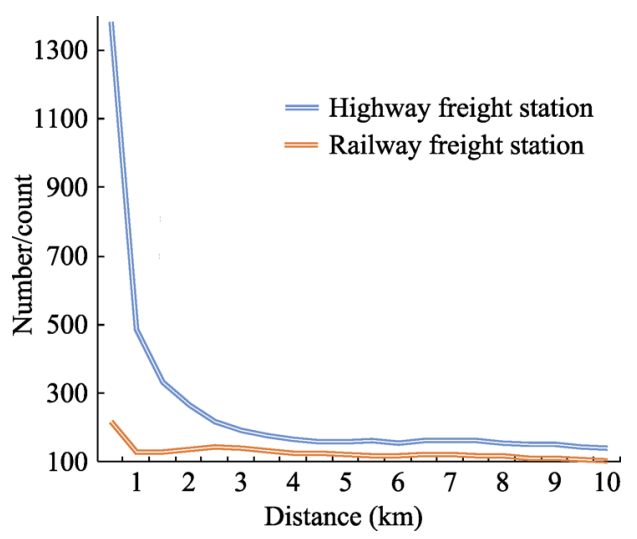

Figure 9 Density distribution of logistics POI around highway and railway freight stations

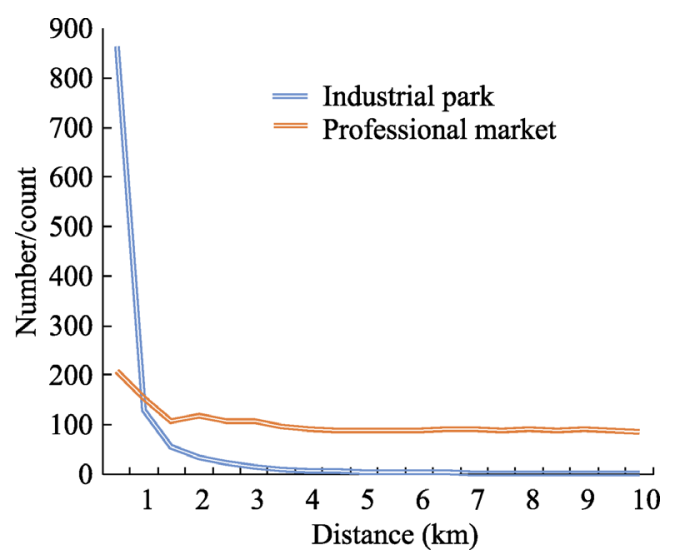

Figure 10 Density distribution of logistics POI in industrial parks and professional markets 
logistics has compromised the efficient organization of urban distribution. Second, professional markets are superior to industrial parks in their agglomeration ability, consistent with the characteristics of logistics enterprises and logistics nodes in commerce and trade services as they are small-scale and large in quantity, and also exhibit differentiation according to the types and targets.

\section{Transportation, land rent, assets and spatial differentiation}

Empirical research on Beijing indicates that the locations of logistics enterprises and logistics nodes show obvious spatial differentiation. The underlying reason is that in the process of logistics location formation, the government attempted to regulate the location choice behavior of enterprises, in order to realize intensive development. This is achieved by a change in the traffic location conditions through planning traffic routes and freight stations, and allocation of logistics warehouse land to affect logistics land rent and availability. On the other hand, enterprises tried to differentiate through asset allocation in order to meet the diverse needs of different clients. The spatial differentiation of logistics nodes and logistics enterprises is the result of government-enterprise interaction. Among them, transportation, rent and assets are the major impact factors for the differentiation in type, function and target of logistics enterprises and logistics nodes. The above process can be explained by the traffic location theory and the land rent theory, as well as the asset specificity theory in economics.

\subsection{Transportation and type differentiation}

The status of transportation as a key element of logistics location choice has not fundamentally changed. Beijing's empirical research data shows that the "ring + radial" transportation network skeleton comprises the core elements of logistics location layout, with $66 \%$ of the logistics nodes and $85 \%$ of the logistics enterprises being concentrated in areas surrounding the network skeleton. Traditional freight station, airport, port etc. have an important role in the culmination of logistics locations. More than $60 \%$ of logistics enterprises and logistics nodes locations are consistent with the aforementioned principles. The transportation dependency of public logistics nodes planned by Beijing are manifested in the following examples: the Shunyi airport logistics base adjacent to the airport, the Majuqiao logistics base adjacent to the 6th Ring Road and the Beijing-Shanghai High-Speed Railway, the Pinggu Mafang logistics base adjacent to the Beijing-Pinggu Expressway and Mafang Railway Freight Station, the Jingnan logistics base near the Beijing-Kaifeng Expressway, as well as the internal construction of 26 special railway lines. However, evidence from the average distance and distance/frequency distribution shows that the linkage between the Beijing transportation facilities and distribution centers is not sufficient. Due to the technical and economic characteristics of various modes of transportation, freeway entrances and freight stations often become layout areas for logistics centers and distribution centers. The logistics parks or logistics bases around railway stations and ports are larger, and air cargo terminals become the layout areas for distribution centers of express enterprises. Type differentiation is significant. Domestic and foreign logistics data shows that the German logistics parks rely more on the development of the original transport hub, while the main purpose of the planned Japanese logistics parks are to solve traffic congestion (Ru et al., 2014). In a survey 
of China's logistics parks in 2015 , more than $62 \%$ of parks have more than two traffic modes, $14 \%$ of parks contain three traffic modes, and $87 \%$ of China's logistics parks layout that focused on traffic convenience. These are consistent with empirical data in Beijing, and have broader applicability. Investigation of enterprises settled in the logistics parks shows that among all enterprises, $85 \%$ are third-party logistics enterprises, $72 \%$ are transportation enterprises, $50 \%$ are express enterprises, and $49 \%$ are freight forwarding enterprises, in agreement with the agglomeration characteristics of public logistics space in Beijing. Overall, the spatial differentiation of traffic locations for different types of logistics nodes and logistics enterprises has been generally accepted (Rivera et al., 2016; Cao, 2012). From the differences among behavioral agents, the larger the scale of the logistics nodes, the higher the degree of government and enterprise cooperation, and the more consistency in location behavior. More than $65 \%$ of China's logistics parks are planned by the government with enterprise-led construction. Similar public-private joint models are also widely used in logistics park constructions in Germany and Japan.

\subsection{Rent and functional differentiation}

The cost of rent and the availability of logistics land in different areas are important factors in the process of choices and changes in logistics locations. Empirical data from Beijing shows that districts and counties located in the inner and outer suburbs have become the focus of the layout of public logistics nodes, while the traditional urban centers and marginal areas are affected by the adjustment of urban functions and exhibit a decline in agglomeration ability. As the major business and office districts, Haidian District and Chaoyang District are still agglomeration areas for the headquarters of many logistics enterprises. The "marginal area of downtown area, suburbs and exurban area" spatial pattern exhibited by Beijing logistics enterprises and logistics nodes is an adequate reflection of functional differentiation. A recent study indicated that logistics enterprises are composed of enterprise attribute elements and logistics attribute elements, which together can easily lead to the functionalization of enterprise departments and the separation of enterprise locations (Zhao et al., 2009). The functions of logistics enterprises were summarized into the following 16 types: headquarters, central office, regional headquarters, regional offices, branch office, service station, operation center, transshipment center, express store, service point, operating station, office, field office, information center, agency and logistics centers (Zong et al., 2015b; Wang et al., 2016). Among them, the location of some function types depends on logistics nodes. Combined with Beijing's empirical data, these functions can be divided into administrative management, business management, and operation and execution. The functions of the administrative management focused mostly in the company headquarters and regional headquarters. They showed the lowest sensitivity to rent, and are located mostly in the city's CBD regions. The business management functions are more concentrated in branch offices, field offices, information centers and agencies. They are moderately sensitive to rent, and are distributed mostly in concentrated commercial and industrial areas in the inner suburb. They often have co-location with administrative offices or operation sites. Operation and execution functions are mainly concentrated in transshipment centers, operating stations and logistics centers. They are most sensitive to rent, and are mostly located in public logistics nodes in the inner or even outer suburbs. 


\subsection{Differentiation of assets and targets}

The importance of asset allocation to logistics nodes and the location of logistics enterprises are gradually increasing, and are changing the existing understanding of logistics locations. Through differentiation of asset allocation, logistics nodes and logistics enterprises meet the needs of different service targets, and promote specialization and division of labor, thus causing target differentiation of the logistics space. Empirical data of Beijing show that spatial differentiation is starting to occur between public logistics space, last-mile distribution space oriented towards specific industries and end consumers, logistics enterprises serving manufacturing needs, and logistics enterprises serving business needs. While the process of differentiation is affected by the adjustment of traffic location and the change of land rent, the role of asset allocation in the process cannot be neglected. According to asset characteristics and asset specificity theory, logistics assets can be divided into current assets and fixed assets according to the difficulty of realization, can be divided into intangible assets and tangible assets according to the asset form, and can also be divided into specific assets and general assets according to the degree of specialization (Xiong et al., 2010). In the stage of traditional logistics, the fixed assets, tangible assets and special assets investments play an important role in the network construction and competitiveness of the logistics enterprises, which in turn solidifies the locations of logistics enterprises and logistics nodes. For example, specialized logistics enterprises operating with hazardous chemicals and bulky cargoes have the characteristics of large investment, poor liquidity, strong specialization, etc., therefore resulting in strong location stability. The production of hazardous materials in Beijing is mainly distributed in Fangshan, Tongzhou, Daxing, with wholesale warehouses concentrated in Daxing, Fangshan and Tongzhou Shunyi Districts. As a result, logistics enterprises engaged in hazardous materials transport are also located in these regions. In the 1970s, FedEx moved to Memphis from nearby Arkansas to build a large freight base, forming large quantities of fixed and specific assets in the process. This not only established Memphis' status as a global aviation logistics hub, but also solidified the headquarters location of FedEx. In the Internet era, informatization and platformization promote innovation in the logistics industry. A large number of new business models, new technologies and new formats are emerging. While this new trend reduces enterprises' transaction costs, at the same time, information, patents, science and technology resources and human capital are increasingly influential in the process of logistics location choice. In general goods, less-than-truck-load, express delivery and other market segments, a large number of platform-based and sci-tech light asset logistics enterprises are emerging. Their space allocation shows significant dynamism, with significantly decreased dependency on transportation and sensitivity to land rent. This exacerbates target differentiation of logistics enterprises and logistics nodes.

Under the influence of the growing metropolitan space and its functional adjustment, logistics locations are spreading from central urban to suburban areas and are experiencing polarization. In the overall process of logistics space differentiation, four distinctive transformations are present. First, the physical attributes (such as weight and volume) of the service targets are shifting from small-size to large-size. Second, the asset attributes of service targets switch from general to professional. Third, the main function of logistics enterprises shifts from office work to operation. Fourth, the types of logistics nodes shift from small 
terminal to larger public facilities. The aforementioned transformation process is not only affected by the location of transportation, land rent and asset allocation costs, but also is a result of the adjustment of producer service demands (mostly manufacturing demand) and demand of living consumption (mostly business service demand) in urban space (Figure 11).

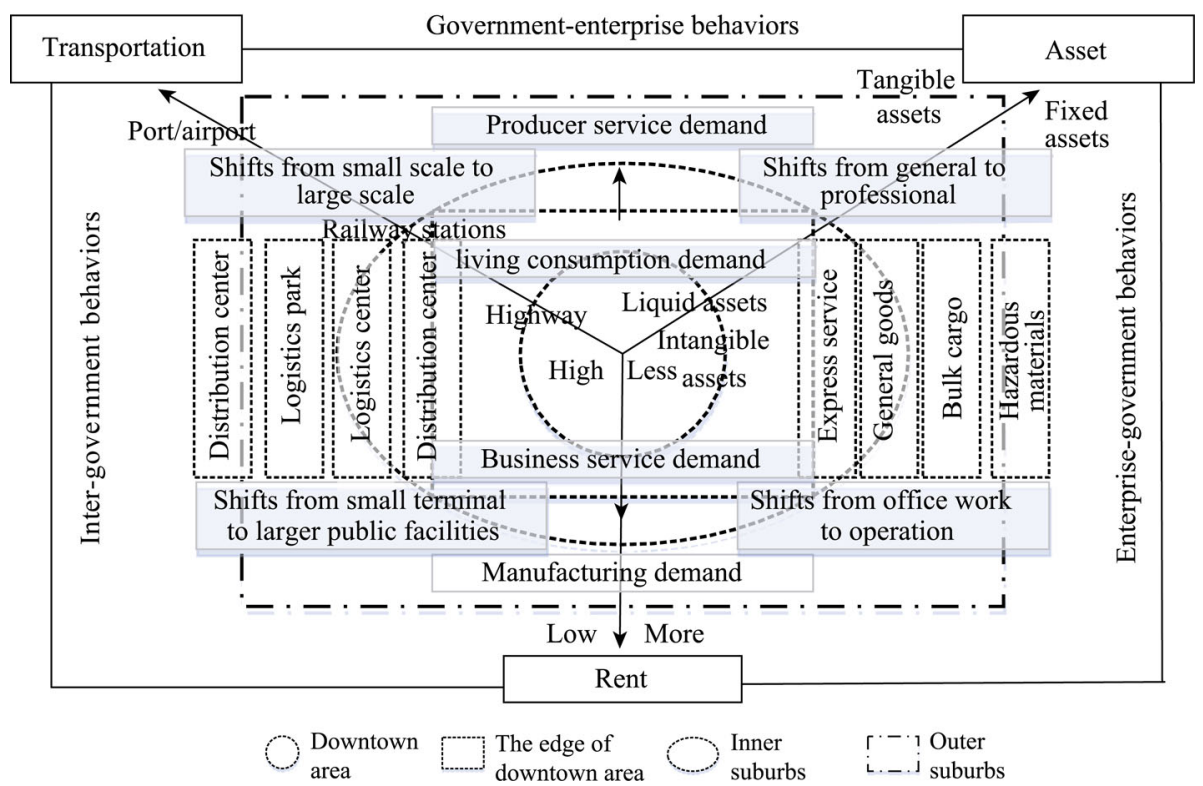

Figure 11 Logistics spatial differentiation process based on "transportation, land rent and asset"

\section{Conclusions and discussion}

Logistics location is the spatial morphology and structures presented on the surface of the planet, of the combined logistics entity network with logistics nodes as its core and the organized logistics networks with logistics enterprises at their core. Its formation is not only the process of satisfying demand, but also the result of reconciliation between the government-planned behavior and the enterprise management behavior. The research results show: (1) in the government-led formation process of public logistics nodes and space, enterprise participation is at a relatively high level, forming a government-planned, enterprise-led development model, which achieves intensive and efficient development. However, during the planning process, the government did not sufficiently consider the consumer-oriented terminal logistics space. Under the combined factors of traffic, land rent and asset allocation, the spatial concentration of enterprise self-built distribution centers is relatively low, and is not sufficiently connected to government-planned public logistics spaces. This increases links and cost of distribution operation, and there is an urgent need to achieve integrated development and unified planning between the public and private sectors. (2) During the process of urban function adjustment and spatial optimization, the dynamics of logistics locations significantly increase, leading to an expedited suburbanization of the layout of logistics nodes. However, due to changes in asset allocation and shifts in business models, the location of some logistics enterprises has not changed significantly. The balance between the 
behavioral differences in government and enterprises is the focus in the optimization of logistics space. (3) Logistics enterprises have different types of assets. Traditional research generally considers logistics nodes as assets of logistics enterprises, while ignoring differences in external assets and asset attributes. This is because during POI data collection and classification, it is difficult to collect types of assets. Therefore, this article investigates the relationship between assets' difficulty of realization, form and degree of speciality and location formation and evolution. In the future, we will further systematically define the sub-categories of assets based on multi-source acquisition tools, in order to perform an in-depth investigation of the roles of assets on the formation mechanisms of different types of nodes and enterprise locations. (4) The types, functions and service industries of existing logistics enterprises are scattered, and did not form a unified standard. Improvement of the classification and coding system is urgently needed in order to systematically explore the effect of service targets on the location choice of logistics enterprises. Compared to questionnaire surveys and enterprise yellow pages, logistics POI information has the advantage of large sample size and complete longitude and latitude coordinates. However, problems still exist such as timeliness and completeness, which require cross-examination with census data. This will improve the integrity and validity of data, further complete the asset and service target attributes of logistics nodes and logistics enterprises, and strengthen the link to economic census data, in order to deepen the location theory of logistics.

\section{References}

Allena J, Brownea M, Cherrett T, 2012. Investigating relationships between road freight transport, facility location, logistics management and urban form. Journal of Transport Geography, 24(9): 45-57.

Cao Weidong, 2011. Spatial pattern and location evolution of urban logistics enterprises: Taking Suzhou as an example. Geographical Research, 30(11): 1997-2007. (in Chinese)

Cao Weidong, 2012. Study on location features and spatial correlation of port enterprises: Taking Shanghai port backup area as an example. Geographical Research, 31(6): 1079-1088. (in Chinese)

Dablanc L, Ogilvie S, Goodchild A, 2014. Logistics sprawl: Differential warehousing development patterns in Los Angeles, California, and Seattle, Washington. Transportation Research Record: Journal of the Transportation Research Board, 2410(12): 105-112.

Dablanc L, Ross C, 2012. Atlanta: A mega logistics center in the piedmont Atlantic megaregion. Journal of Transport Geography, 24(9): 432-442.

Hesse M, Rodrigue J P, 2004. The transport geography of logistics and freight distribution. Journal of Transport Geography, 12(3): 171-184.

Li Guoqi, Jin Fengjun, Chen Yu et al., 2015. Spatial patterns of logistics industry based on a geographic analysis of hotness degree. Progress in Geography, 34(5): 629-637. (in Chinese)

Lin Xiaowei, Shu Hui, Yin Gongli, 2013. An empirical analysis of co-integration relationships among logistics, export and economic growth. Prices Monthly, (11): 12-15. (in Chinese)

Liu Haiyan, Li Zongping, Ye Huaizhen, 2000. Logistics distribution center allocation model. Journal of Southwest Jiaotong University, 35(3): 311-314. (in Chinese)

Mao Haijun, Zhang Yong, Li Xuhong, 2005. Logistics enterprise classifying model. Journal of Traffic and Transportation Engineering, 5(2): 117-121. (in Chinese)

Meng Bin, 2009. The spatial organization of the separation between jobs and residential locations in Beijing. Acta Geographica Sinica, 64(12): 1457-1466. (in Chinese)

O'Connor K, 2010. Global city regions and the location of logistics activity. Journal of Transport Geography, 
18(3): 354-362.

Pan Yujuan, Cao Xiaoshu, 2012. Spatial patterns and their formation mechanism of supply logistics network of wholesale markets in Guangzhou. Acta Geographica Sinica, 67(2): 179-188. (in Chinese)

Rivera L, Sheffi Y, Desirée K, 2016. Logistics clusters: The impact of further agglomeration, training and firm size on collaboration and value added services. International Journal of Production Economics, 179(9): 285-294.

Rivera L, Sheffi Y, Welsch R, 2014. Logistics agglomeration in the US. Transportation Research Part A: Policy and Practice, 59(11): 222-238.

Ru Yihong, Tian Yuan, 2014. Logistics. 2nd ed. Beijing: Higher Education Press. (in Chinese)

Sule D R, 2001. Logistics of Facility Location and Allocation. New York: Marcel Dekker.

Takanori S, Kazuya K, Tetsuro H, 2015. Locational dynamics of logistics facilities: Evidence from Tokyo. Journal of Transport Geography, 46(6): 10-19.

Taniguchi E, Noritake M, Yamada T et al., 1999. Optimal size and location planning of public logistics terminals. Transportation Research Part E: Logistics and Transportation Review, 35(3): 207-222.

Van den Heuvel F P, de Langen P W, van Donselaar K H et al., 2013. Regional logistics land allocation policies: Stimulating spatial concentration of logistics firm. Transport Policy, 30(12): 275-282.

Verhetsel A, Kessels R, Goos P et al., 2015. Location of logistics companies: A stated preference study to disentangle the impact of accessibility. Journal of Transport Geography, 42(1): 110-121.

Virginia G, 2004. Careers and recruitment: Mapping opportunities. Nature, 427: 376-377.

Wang Chengjin, 2008. Spatial organizational network of logistics company in China. Acta Geographica Sinica, 63(2): 135-146. (in Chinese)

Wang Chengjin, 2014. Space Network Mode and Organization Mechanism of Logistics Enterprises. Beijing: Science Press. (in Chinese)

Wang Chengjin, Li Guoqi, 2016. Entrance of international logistics firms into mainland of China and its spatial network. Human Geography, 31(4): 72-79. (in Chinese)

Xiong Dezhang, Liu Qiaoqiao, 2010. Review and reflection of the asset specificity theory. Modern Management Science, (5): 75-78. (in Chinese)

Xu Shoubo, 2007. The Material Flow (Cont.). China Business and Market, 21(10): 7-10. (in Chinese)

Yuan Qingda, Du Wen, Li Qingsong, 2001. The size and location of region public logistics center. Journal of Traffic and Transportation Engineering, 1(4): 97-100. (in Chinese)

Zhang Yongzhong, Bai Jingyu, 2010. Public logistics area planning: A case study of spatial planning for public logistic area in Beijing. City Planning Review, (11): 31-34, 39. (in Chinese)

Zhao Yongbo, Han Zenglin, 2009. The development and distribution of producer services in Dalian. Journal of Liaoning Normal University (Natural Science Edition), 32(4): 500-504. (in Chinese)

Zong Huiming, Wang Pengcheng, Dai Jicai, 2015. The spatial layout of logistics parks in Chongqing urban area and its impacts on the urban structure. Scientia Geographica Sinica, 35(7): 831-837. (in Chinese)

Zong Huiming, Zhou Suhong, Yan Xiaopei, 2015. Research on the spatial network of local comprehensive third-party logistics company under globalization: Taking Tengbang Logistics Company as a case. Geographical Research, 34(5): 944-952. (in Chinese) 